\title{
ENSINO DE CIÊNCIAS: UM PANORAMA MULTIFOCAL
}

\author{
Tanise Knakievicz \\ Pós-doutora em Ensino de Ciências - Doutora em Biologia Celular e Molecular - \\ Bióloga - Especialista em Dinâmica de Grupos SBDG - Diretora Executiva do Espaço Multiverso \\ $\triangle$ knakievicz@gmail.com
}

\begin{abstract}
Resumo:
As constantes transformações socioculturais e tecnocientíficas promovem mudanças nas estratégias didáticas no cotidiano escolar. Disponibilizar um mapa panorâmico deste território dinâmico é o objetivo deste artigo. Assim, discorrera-se sobre o ensino de Ciências quanto aos aspectos históricos, sociais, paradigmáticos, culturais, políticos, econômicos e neuropsicológicos, destacando a priorização dos conteúdos atitudinais na educação básica. A ação didática focada no desenvolvimento de habilidades e competências coloca os estudantes sob holofotes dos professores, deslocando os conteúdos conceituais e procedimentais a cenários coadjuvantes.
\end{abstract}

Palavras-chave: Cultura tecnocientífica; Senso de dignidade; Didáticas participativas; Cultura da paz.

\section{SCIENCE EDUCATION: AN MULTIFOCAL OVERVIEW}

\begin{abstract}
:
The constant sociocultural and technoscientific transformations promote changes in teaching strategies in everyday school life. To Provide a panoramic map of this dynamic territory is the purpose of this article. Thus, we will talk about the teaching of science as the historical, social, paradigmatic, cultural, political, economic and neuropsychological, highlighting the prioritization of attitudinal content in basic education. The didactic action focused on developing skills and competencies puts students under floodlights teachers, shifting the conceptual and procedural contents to supporting scenarios.
\end{abstract}

Keywords: Techno-scientific culture; Dignity of sense; Participatory teaching; Culture of peace.

\section{EDUCACIÓN CIENTÍFICA: UN RESUMEN MULTIFOCAL}

\section{Resumen:}

Las constantes transformaciones socioculturales y tecnocientíficos promueven cambios en las estrategias de enseñanza en la vida escolar cotidiana. Proporcionar un mapa panorámico de este territorio dinámica es el propósito de este artículo. Por lo tanto, vamos a hablar de la enseñanza de la ciencia como el histórico, social, paradigmático, cultural, política, económica y neuropsicológico, destacando la priorización de los contenidos actitudinales en la educación básica. La acción didáctica centrada en el desarrollo de habilidades y competencias pone a los estudiantes con luz artificial maestros, cambiando los escenarios conceptuales y de procedimiento que apoyan el contenido.

Palabras clave: Cultura tecnocientífica; Censo de Dignidad; Didácticas Participativas; Cultura de la paz. 


\section{INTRODUÇÃO}

No site Inovação Tecnológica ficamos a par da incrível capacidade inventiva humana (INOVAÇÃO TECNOLOGIA, 1999). Quem são os protagonistas desta realidade tão distante do cotidiano, que mais parece ficção científica? Parece lógico pensar que são pessoas com habilidades e inteligências incomuns e totalmente independentes da realidade do ensino de ciências nas escolas, e até mesmo de muitas universidades. Assim, a escola não pertencendo a esse grupo de pessoas extraordinárias, sente-se rejeitada e incrédula quando ao processo educativo, reforçando as crenças da origem das desigualdades sociais estarem além das ações cotidianas dos sistemas educacionais.

As desigualdades sociais nas comunidades da América Latina causam preocupações, pois em situações de pobreza extrema as famílias desestruturam, a corrupção e a criminalidade aumentam, a coesão social diminui, levando a fragmentação de todos os níveis: o cultural, o social e o econômico. As causas destas desigualdades extremas são históricas, econômicas e culturais. No entanto, o investimento na qualificação da educação e na promoção de igualdades de oportunidades sociais de partida e não de chegada são ações factíveis aos Estados (COTLER, 2011).

O elemento chave do desenvolvimento da civilização humana foi a comunicação via linguagem simbólica (RIBAS, 2006), a base tecnológica do ensino em todos os níveis de escolaridade. A linguagem baixa o custo energético de aquisição de novas habilidades e multiplica os benefícios das competências já adquiridas, ou seja, a comunicação otimiza e potencializa o tempo-espaço da aquisição e compartilhamento de novas informações e habilidades (JABLONKA; LAMB, 2010).

A proposta desde artigo é fornecer uma visão panorâmica multifocal das ações da comunidade escolar. O ensino de ciências será abordado sob enfoques históricos, sociais, paradigmáticos, culturais, políticos, econômicos, pedagógicos e psiconeurológicos, destacando a reflexão a respeito da prioridade dos conteúdos atitudinais no Ensino fundamental. A escola é a fonte promotora da sociedade científica e ao mesmo tempo é pressionada por essa sociedade que criou a reformular-se, a adaptar-se, estando constantemente no fronte das crises adaptativas decorrentes das inovações tecnológicas. 


\section{O ENSINO DE CIÊNCIAS E AS ONDAS CIVILIZATÓRIAS}

Segundo Toffler (2012), três grandes ondas de transformação civilizatórias ocorreram: a Revolução Agrícola - $1^{\text {a }}$ onda; a Revolução Industrial - $2^{\mathrm{a}}$ onda; e a Revolução Tecnológica - $3^{\mathrm{a}}$ onda (Figura 1). O aparecimento da agricultura foi o primeiro ponto decisivo para o desenvolvimento social humano e teria dominado a Terra até meados dos anos de 1650 ou 1750. A partir de então, o acesso à civilização industrial teria começado a ganhar força, surgindo a $2^{\mathrm{a}}$ onda e os novos paradigmas passaram a ser determinados pelos processos produtivos padronizados em massa, gerando a urbanização e a formação de uma sociedade industrial. Os produtos resultantes da Revolução Industrial permitiram a divulgação rápida da informação, a conectividade emergindo assim a $3^{\mathrm{a}}$ onda, por volta dos anos 1950. Um mundo estruturado a partir do fluxo intenso da informação e do conhecimento, está permitindo que a $4^{\mathrm{a}}$ onda surja a partir da hiperconectividade e hipercomunicação globalizadados achados científicos da natureza da matéria e da consciência (SILVA, 2006; RENVNOSUO, 2010; SHELDRAKE, 2014; VIEIRA, 2014).

Figura 1: Modelos representativos das ondas de transformação da civilização humana.

A

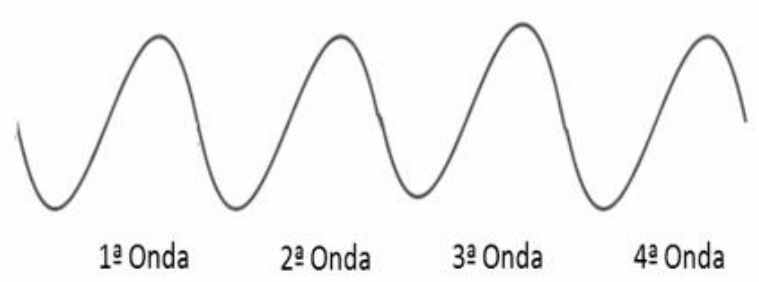

B

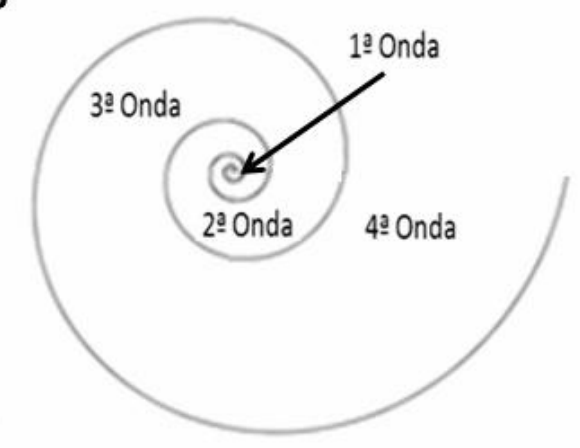

Legenda: $1^{\mathrm{a}}$ onda: Revolução Agrícola; $2^{\mathrm{a}}$ onda: Revolução Industrial; $3^{\mathrm{a}}$ onda: Revolução Tecnológica; $4^{\mathrm{a}}$ onda: Evolução Consciencial. A. Modelo de propagação de ondas no espaço-tempo em sequências linear, leva a interpretar que a complexidade se mantém constante. Modelo espiral hiperbólica a propagação de ondas novas se somam as anteriores acrescendo novos níveis de informação, e leva a interpretar que a complexidade aumenta.

Na Revolução Agrícola surge a linguagem simbólica e escrita e o sistema de educação formal restrito a uma pequena parcela da população. Na Revolução Industrial, o ensino básico expande-se aos trabalhadores, e há uma relativa aceleração das transformações históricas, 
sociais, econômicas e culturais, as quais refletem-se nas propostas de reforma do ensino de ciências. Na revolução Tecnológica, surge a necessidade da formação continuada do cidadão tecno-cientificamente autônomo, hábil, responsável e ético (KRASILCHIK, 2000; TOFFLER, 2012).

A busca de ajustar a educação às mudanças já estabelecidas na Revolução Industrial e as demandas emergentes do mundo tecnológico e globalizado pode ser visualizada quadro a quadro nas reformas das diretrizes curriculares da Ensino de ciências, refletindo a transição paradigmática da $2^{\mathrm{a}}$ para a $3^{\mathrm{a}}$ onda civilizatória. Por exemplo, no Brasil, a década de 1950 foi o marco inicial da participação do governo na normatização da educação científica, em todos os níveis, na medida em que a Ciência e a Tecnologia foram sendo reconhecidas como essenciais no desenvolvimento econômico, cultural e social, no auge da Revolução Industrial ( $2^{\mathrm{a}}$ onda). As reformas nos parâmetros curriculares nacionais da educação básica no Brasil das décadas de 1950 e 1970 objetivam primeiro a formação do trabalhador apto para os processos produtivos industriais e depois a formação de uma elite pensante para atender os objetivos da Guerra Fria e da Guerra Tecnológica. E estavam alinhadas com o estabelecimento da segunda onda e o começo da terceira, respectivamente (KRASILCHIK, 2000).

As diretrizes atuais de Ensino estabeleceram que a educação escolar deve vincular-se ao mundo do trabalho e à prática social, incluindo a formação ética, a autonomia intelectual e a compreensão dos fundamentos científico tecnológicos dos processos produtivos (BRASIL, 1997; 2006). A formação do cidadão-trabalhador-estudante tem caráter permanente e continuado para atender o atual contexto social globalizado (KRASILCHIK, 2000). As diretrizes educacionais desta proposta ainda não estão efetivamente implementadas, pois na prática, ainda o sistema de ensino reproduz o ambiente curricular da Revolução Industrial pela manutenção dos métodos de ensino padronizados e validados naquele contexto. Assim, esse momento reflete a crise paradigmática de Ensino de Ciências, que ainda opera segundo as normas vigentes das reformas da década de 1950 e 1970, contudo, essa formação é dissonante com o contexto social globalizado contemporâneo.

Os recursos tecnológicos atuais e a flexibilização nos Parâmetros Curriculares Nacionais (PCNs), abrem espaços para novas possibilidades de ensino venham a ser criadas e testadas, alinhando a formação educacional básica com as demandas do mundo contemporâneo globalizado (BRASIL, 1997; 2006). Por exemplos: a Escola Lumiar, sem 
salas de aulas (SEMLER et al. 2004), a Escola da Ponte em Portugal (PACHECO, 2009), a Escola de Rede organizada por Augusto de Franco (ESCOLA DE REDES, 2011), o projeto Khan Academy (KHAN, 2013), o Projeto Amora do Colégio de Aplicação da UFRGS (PROJETO AMORA, 2016), o método de aprendizagem colaborativa da Faculdade Uniamérica (UNIAMÉRICA, 2016).

O processo educacional informal parece ser decisivo para delimitar o início enquanto que o processo educacional formal parece entrar em crise no fim de cada onda revolucionária. Assim, o papel da educação básica formal parece atuar, paradoxalmente, na contra-mão do processo de desenvolvimento socioeconômico, uma vez que realimenta uma formação cognitiva desatualizada e consequentemente, a manutenção da crise no ensino.

As inovações pontuais determinariam o início do próximo ciclo de uma onda e a conclusão do ciclo se dá pela globalização destas inovações pelo processo de educação formal, até que essas informações sejam assimiladas ou tornem-se desnecessárias pois o contexto mudou, e outras inovações adaptativas sejam requeridas. Neste cenário dinâmico de mudanças culturais e tecnológicas, as diretrizes de ensino formal, em cada novo cenário passarão, naturalmente, por reformas de modo ajustar a educação formal às inovações decorrente da pressão adaptativa. Pode-se concluir que a formalização do ensino, tem no seu DNA o tradicionalismo, essência fixadora de rotinas, que paradoxalmente, gera inovações.

\section{O ENSINO DE CIÊNCIAS E A ESTRUTURA SOCIAL}

As mudanças nos paradigmas educacionais, segundo Augusto de Franco, dependem da estrutura organizacional da topologia da rede social (FRANCO, 2009). As pessoas de uma sociedade podem organizarem-se quanto a seu comportamento de 3 modos diferentes, gerando as topologias centralizada, descentralizadas e distribuídas (Figura 2). 
Figura 2: Topologia de Rede Social.
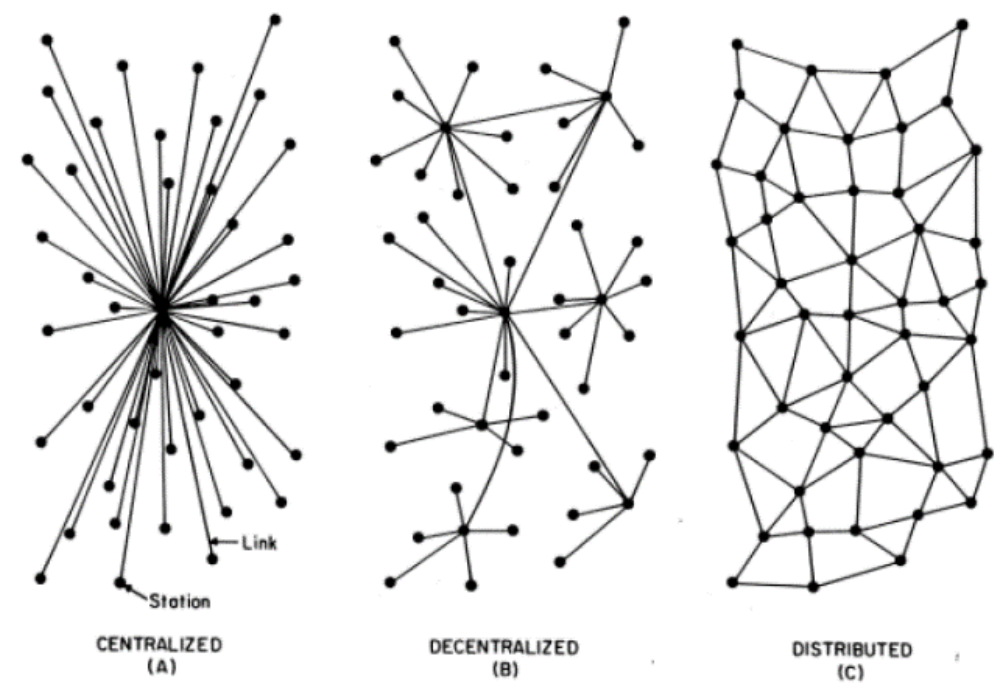

Legenda: A. Rede centralizada, tais como nos regimes monárquicos e no sistema feudal são altamente hierárquicas. B. Rede descentralizada é a mais comum na sociedade contemporânea, configurando as relações hierárquicas diversas das instituições de ensino, das igrejas, das empresas, das ONGs, e do sistema industrial. C. Rede distribuída ocorre na ausência de poder hierárquico em especial devido as possibilidades de todos interagirem com todos por meio das tecnológicas atuais, configurando as interações sociais da democracia pura.

Fonte: BARAN, 1964.

Do ponto de vista das redes o poder é o poder de centralizar nodos por obstrução, separação, exclusão ou desconexão de nodos ou clusteres particulares da rede, e assim concentrar para si o máximo de conexões em relação aos outros. Entre a monocentralização e a distribuição máxima existem muitos graus de distribuição. É entre esses dois limites que se estabelece a maioria das redes realmente existentes. A questão mais importante da topologia das redes, diz respeito de que elas dependente não dos atores, mas do comportamento destes, podendo haver fluidez de uma topologia a outra conforme o contexto e o comportamento dos atores (FRANCO, 2009).

Considera-se que o comportamento é dado pelo modo com que cada ator lida com as atitudes de apoderamento e empoderamento. $\mathrm{O}$ apoderamento (a-poder, não-poder), exercício de controle sobre o outro, é composto de duas contrapartes: a abdicação do autopoder e a autocracia. Esse tipo de poder é funcional e necessário no cuidado parental de crianças muito pequenas e/ou de incapazes, estabelecendo-se devido a presença de algum grau de dependência funcional, emocional, ou econômica. O empoderamento, exercício de controle 
sobre si mesmo, também é composto de duas contrapartes: a assunção do autopoder e a democracia. A transição entre ambas topologias de rede é determinada pela soma das experiências pessoais no contexto vivenciado em questão.

O sistema educacional quando surgiu na época medieval, estabeleceu-se com um sistema de rede social altamente centralizada, aos moldes da monarquia e do clero, pois somente essas classes sociais tinham acesso ao conhecimento e as tecnologias de informação. Também nesta época não existia o conceito de instituição pluridisciplinar, pois a universidade surge das igrejas e também como igrejas, e por meio do tradicionalismo educacional tem permanecido funcionando segundo a lógica da racionalidade sacerdotal. A universidade passou por várias reformas estruturais (cirurgias plásticas), contudo o seu DNA permanece inalterado, pois os professores (mestres) transmitem seus ensinamentos aos alunos (discípulos), com a intenção de controle e influência sobre a sociedade por parte de seus instituidores: a realeza e o papado (FRANCO; LESSA, 2012).

O aparecimento das universidades foi uma inovação social importante, pois permitiu que os estudiosos se organizassem em uma corporação e se destacassem da massa dos ignorantes. Contudo, consolidaram-se como instituições avessas à democracia, mantendo o saber fechado em suas próprias corporações. A Universidade criou a separação entre um corpo docente e um corpo discente e a visão do conhecimento como conteúdo arquivável e transferível e não como resultado de interação social (FRANCO; LESSA, 2012). O que surgirá no lugar dessas instituições medievais que permanecem na contemporaneidade?

\begin{abstract}
O surgimento da Universidade (medieval) foi uma expressão do mundo (medieval), da cidade (medieval), da topologia da rede social da época, dos seus baixos graus de distribuição, conectividade e interatividade. Nos mundos altamente conectados que estão emergindo no terceiro milênio, não haverá mais lugar para algo como uma universidade. Em termos sociais já estamos em um multiverso (distribuído) não em um (único) universo (centralizado). Assim, precisamos agora de multi-versidades. A cidade vertical, murada e fortificada, administrada autocraticamente, onde surgiu a universidade, dará lugar agora à cidade-rede onde surgirá a multiversidade democratizada (FRANCO; LESSA, 2012, p. 12-13).
\end{abstract}

Como se dará a transição dos comportamentos favoráveis à aprendizagem-criação abertos? Quais os comportamentos otimizadores da organização social segundo o padrão de rede distribuída, diversa e múltipla? A multiversidade é um marco da $4^{\mathrm{a}}$ onda civilizatório? Para buscar respostas a tais indagações segue a análise da crise atual no ensino de Ciências. 


\section{ENSINO DE CIÊNCIAS E A TRANSIÇÃO PARADIGMÁTICA}

Paradigma é literalmente modelo, é a representação de um padrão a ser seguido (KUHN, 1998). É um pressuposto filosófico, matriz, ou seja, uma teoria, um conhecimento que origina o estudo de um campo científico com métodos e valores que são concebidos como modelo; uma referência inicial como base de modelo para estudos e pesquisas. Os paradigmas modelam comportamentos. Segundo Kuhn (1998), uma comunidade científica consiste de pessoas que partilham um dado paradigma e estas ao adquirirem este paradigma, adquirem concomitantemente critérios para a percepção da realidade, para a análise de problemas e para o julgamento de comportamentos.

A partir da reflexão da crise na educação de ciências (ACADEMIA BRASILEIRA DE CIÊNCIAS, 2008; BRITO; RAMOS, 2014), propõe-se dois paradigmas hipotéticos, o paradigma universal e o multiversal, analisados analogicamente por meio da cladística ${ }^{1}$ e dos termos pleisiomórfico² e apomórfico ${ }^{3}$ (FUTUYMA, 2009, p. 95). O paradigma universal, pleisiomórfico, primitivo, mãe ou formativo diz respeito a formação escolar disciplinar dos formadores, professores, e o paradigma multiversal, apomórfico, derivado, filho diz respeito ao mercado de atuação profissional atual, inclusive dos formadores (docentes) e dos formados (discentes) (Quadro 1).

Ambos os paradigmas, o universal (plesiomórfico e ancestral) e o multiversal (apomórfico e derivado) foram ou são operacionalmente eficientes em si em um dado contexto, mas quando se sobrepões no mesmo espaço, podem causar desestruturações recíprocas, e assim geram-se crises. Essas crises, até um certo ponto, são inevitáveis. Pois, o paradigma multiversal surge do acúmulo dos saberes resultantes da somatória das produções intelectuais do paradigma universal de diversas áreas do saber, e esses saberes ao intercorrelacionarem dão origem ao novo paradigma (Figura 3).

\footnotetext{
${ }^{1}$ A Cladística ou sistemática filogenética é um método de classificação biológica hierárquica a partirdo grau de semelhança global do máximo de carateres possíveis entre espécies. Os caracteres são classificados em: presentes ou ausentes e plesiomórfico ou apomórfico.

${ }^{2}$ Plesiomorfia: Um estado de caráter ancestral, primitivo em relação a outro estado derivado.

${ }^{3}$ Apomorfia: Um estado de caráter derivado, avançado em referência a outro estado ancestral.
} 
Quadro 1: Análise comparativa entre os paradigmas acadêmicos universal (pleisiomórfico, ancestral) e multiversal (apomórfico, derivado).

\begin{tabular}{|c|c|c|}
\hline TEMA & $\begin{array}{l}\text { PARADIGMA ÚNICA } \\
\text { VERSÃO }\end{array}$ & $\begin{array}{l}\text { PARADIGMA MULTI } \\
\text { VERSÕES }\end{array}$ \\
\hline Ensino & $\begin{array}{l}\text { Linear e artificial. Sistematização } \\
\text { por meio da simplificação. } \\
\text { Prioriza conteúdos } \\
\text { sequencialmente no tempo-espaço. }\end{array}$ & $\begin{array}{l}\text { Complexa e Neurofisiológica. } \\
\text { Interconexão e Complexificação. } \\
\text { Prioriza a aquisição de } \\
\text { competências e habilidades. }\end{array}$ \\
\hline Foco & $\begin{array}{l}\text { Formar uma elite e/ou cidadão- } \\
\text { trabalhador. }\end{array}$ & $\begin{array}{l}\text { Formar cidadão-trabalhador- } \\
\text { estudante autodidata. }\end{array}$ \\
\hline Atuação & Setorial, normativa e reguladora. & Integrativas e escalonáveis. \\
\hline Emoções & $\begin{array}{l}\text { Reações instintivas emocionais } \\
\text { recalcadas: emoções são tabus. }\end{array}$ & $\begin{array}{l}\text { Ações reflexivas integrais: } \\
\text { inteligência emocional. }\end{array}$ \\
\hline Inovações & A criatividade é um risco a erros. & $\begin{array}{l}\text { A criatividade é o efeito das } \\
\text { cooperações multidisciplinares. }\end{array}$ \\
\hline $\begin{array}{l}\text { Modus } \\
\text { operanti }\end{array}$ & $\begin{array}{l}\text { Processos visam manter o status } \\
\text { quo. Há proteção da divulgação do } \\
\text { como fazer. Foco nos Resultados. }\end{array}$ & $\begin{array}{l}\text { Processos visam soluções. } \\
\text { Transparências do como fazer. } \\
\text { Foco nos procedimentos. }\end{array}$ \\
\hline Sucesso & $\begin{array}{l}\text { Ser aceito é ter. Ter um território, } \\
\text { valor social é em função de ter um } \\
\text { título, posto, cargo. }\end{array}$ & $\begin{array}{l}\text { Ser aceito é ser percebido. Ser } \\
\text { interconectado, valor social é em } \\
\text { função do trabalho realizado. }\end{array}$ \\
\hline Dimensão & $\begin{array}{l}\text { Unidimensional, há limites claros } \\
\text { e precisos entre as áreas do saber. }\end{array}$ & $\begin{array}{l}\text { Multidimensional, as áreas do } \\
\text { saber se fundem para formam } \\
\text { novas áreas, produtos e serviços. }\end{array}$ \\
\hline $\begin{array}{l}\text { Pontos de } \\
\text { intersecção }\end{array}$ & $\begin{array}{l}\text { Local de disputa de poder e de } \\
\text { crises paradigmáticas. }\end{array}$ & $\begin{array}{l}\text { Locais de intercâmbios de } \\
\text { conhecimentos e de inovações. }\end{array}$ \\
\hline Liderança & $\begin{array}{l}\text { Poder exercido por cargo ou } \\
\text { titulação. }\end{array}$ & Liderança exercida por expertise. \\
\hline
\end{tabular}


Figura 3 - Modelos esquemáticos hipotéticos dos paradigmas atuantes no ensino e na produção científica.

A

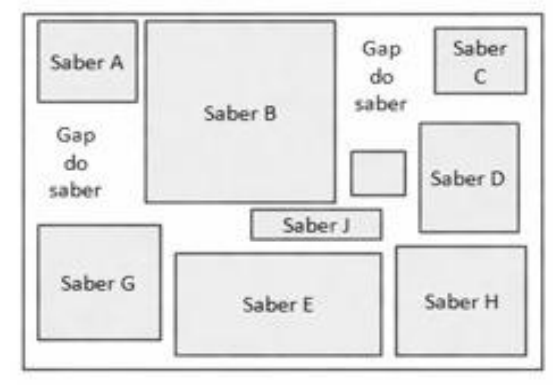

B

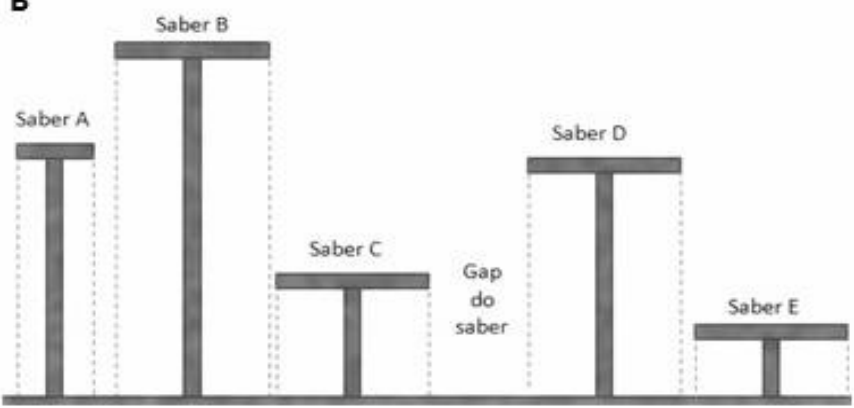

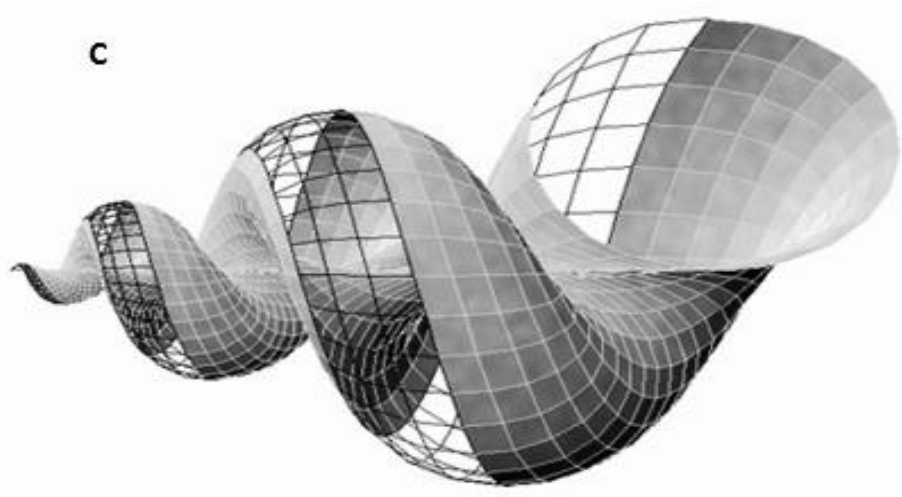

Legenda: A.Visão panorâmica dos territórios disciplinares do conhecimento científico tradicional. A linha em torno dos saberes estabelece o limite entre ciências e pseudociências. B. Visão da estrutura vertical da atuação acadêmica por território de saberes. Cada saber estabelece sua supremacia por ordem cronológica de surgimento e estabeleceu suas fronteiras. C. Cone em espiral hiperbólico. As paredes representam as áreas disciplinares do saber, (asseguram limites pelo estabelecimento de premissas ou dogmas científicos) e as paredes vazadas mostram os pontos cegos, ou não percebidos da realidade como problema científica. O centro do cone é o espaço de intercâmbios de saberes e produção de inovações. A abertura do cone representa a fronteira com o desconhecido/percebido.

A aparente distorção no status quo dos saberes que se aproximam entre si tempoespacialmente, deixa de promover a sensação de segurança entre o que se sabe e o que não se sabe, aumentando as incertezas quando aos saberes já adquiridos, gerando necessidade de revisitação destes a partir de outros prismas. O desconforto emocional diante destas incertezas ativa as respostas neurofisiológicas mais antigas, mais reativas, e.i., as respostas do sistema límbico, assim a natureza biológica humana, se irrefletida, tende a promover a resistência ao diferente e rejeitar as propostas de mudanças (VILLA, 2008; CARTER, 2012; DUHIGG, 2012). 
Consequentemente, o conflito no ensino de ciências, pode estabelecer-se por estarmos operando por hábito a nível neuromuscular em favor do paradigma universal (rede social centralizada e hierárquica) e ao nível mental cognitivo em favor do paradigma multiversal (rede social distribuída e democracia)? Moisés Bertoni, no final do sec. XIX, já havia observado que a origem dos conflitos sociais é devido à natureza bioculural humana (BUTTURA; NIEMEYER, 2012, p. 124). Embora o homem em sua natureza moral anseie por mudanças, paradoxalmente, se desorienta ao lidar com elas. Portanto, a crise paradigmática decorre da natureza neurofisiológica fixadora de hábitos em conflito com a natureza moral ávida por novidades e mudanças (DUHIGG, 2012, p. 35; MATURANA; VARELA, 1995, P. 43).

Esse processo de mudança de paradigma parece ser uma ação não exclusivamente racional e lógica, mas fisiológica e emocional. Sabe-se que em situações de estresse o cérebro naturalmente adota o comportamento mais primitivo, resultando em comportamento conservador (LUSKIN; PELLETIER, 2008, p. 48). E esses aspectos, não intelectivos, promovem comportamentos de apego instintivo ao já conhecido e de rejeição do novo, mesmo este último sendo uma escolha intelectual legítima. Tem-se por hipótese, que a força de resistência possa ser gradativamente cedida à medida que a formação científica multidisciplinar deixa de ser novidade e passe a ser um elemento comportamental natural do contexto escolar, social e cultural.

\section{ENSINO DE CIÊNCIAS E AS INOVAÇÕES}

A ciência é uma atividade social promotora de inovações. O processo evolutivo científico e seus produtos, pode ser ilustrado através da analogia da origem do oxigênio atmosférico e dos organismos fotossintetizantes.

O oxigênio, inexistente atmosfera primitiva e indispensável a vida da grande maioria dos organismos atuais, surgiu como subproduto tóxico do metabólico dos organismos ancestrais autotróficos, os primeiros seres fotossintetizantes. Por milhões de anos, a produção de oxigênio era absorvida pelas rochas sem alterar a concentração atmosférica, contudo, uma vez saturadas as rochas, a presença do oxigênio atmosférico aumentou quase que instantânea. Muitos organismos foram extintos, exceto aqueles que restringiram-se em espaços 
desprovidos de oxigênio ou aqueles com adaptações e recursos enzimáticos para utilizar o oxigênio neutralizando a sua toxicidade. A partir dos organismos ancestrais dotados de maquinaria molecular capaz de processar e utilizar o oxigênio atmosférico surgiu uma grande diversidade de organismos aeróbicos, inclusive a espécie humana.

De modo similar ao descrito anteriormente, os produtos e subprodutos das atividades científicas das gerações que nos antecederam e nos orientaram, é o "oxigênio" que vem se acumulando lentamente nas estruturas sociais, e então, de um momento para outro, novas atmosferas culturais podem emergir, de modo aparentemente súbito e espontâneo.

Como selecionar e metabolizar as novas informações e os novos produtos em contínua expansão sem se intoxicar? Como desenvolver critério de seleção de absorção e enzimas de digestão cognitiva destes aportes nutricionais intelectivos produzidos pelas gerações que nos antecederam? Das informações e os conhecimentos disponíveis, quais são os mais prioritários assimilarmos para continuarmos evoluindo em complexidade, harmonia e homeostase?

\section{ENSINO DE CIÊNCIAS E AS HABILIDADES CIENTÍFICAS}

Uma vez que um paradigma é utilizado como padrão correto de interpretar e estudar a natureza e as relações sociais, surgem consequências. Uma das questões mais séria a respeito da Ciência é o fato desta ser tomada por um sistema de crenças (SHELDRAKE, 2014). Existe a crença difundida na sociedade de que a Ciência já entende a Natureza em seus princípios básicos, só restando detalhes a serem preenchidos. Esse modo de pensar gera uma visão de mundo padrão, e a partir desta referência-padrão estabelece-se o que é possível e não possível ocorrer na natureza (figura 4). Hoje, questionar algumas verdades científicas requer uma certa dose de ousadia, em especial porque o sistema de educação não incorpora na integra a essência da ciência em suas estratégias didáticas, e.i., o princípio da falseabilidade de Karl Popper (SILVEIRA, 1994) e o princípio da descrença (VIEIRA, 2014, p. 704).A veracidade e permanência de uma teoria científica independe da quantidade de observações positivas, pois pode ser falseada (refutada) por uma única observação negativa, segundo o princípio da falseabilidade. Segundo o princípio da descrença, nenhuma ideia deve aceita de maneira apriorista, dogmática ou mística; mas somente após demonstrações práticas e análises críticas, desapaixonadas, refletidas e racionais. 
Figura 4 - Mapa conceitual das estratégias de ensino de ciências.

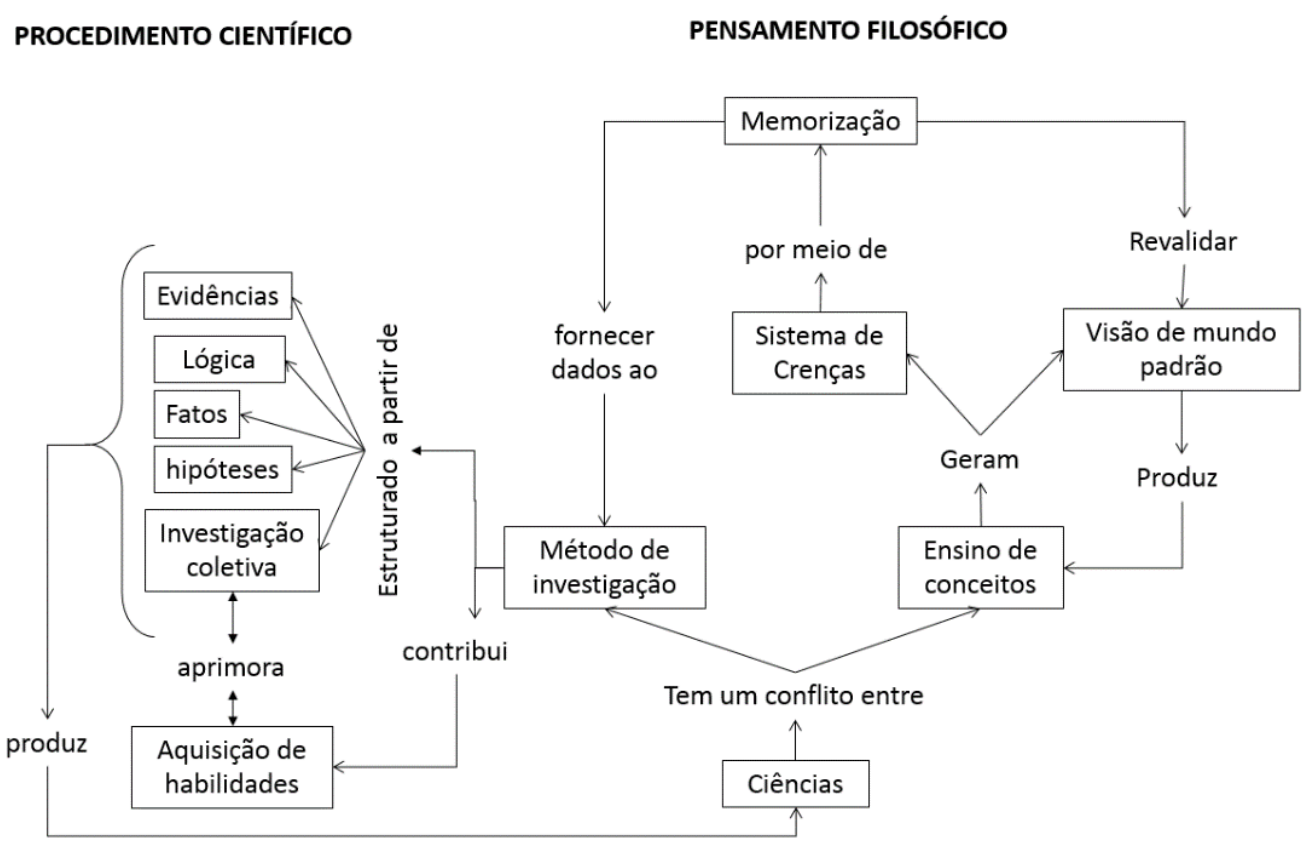

Legenda: As rotas de aprendizagem de Ciências a partir de procedimentos científicos e do pensamento filosófico. Visão geral das Ciências como método de investigação e/ou como um sistema de crenças.

O mundo tecnológico contemporâneo foi sendo construído pouco a pouco a partir da aplicação multidisciplinar dos conhecimentos científicos, os quais surgem a partir da observação sistematizada e racional da realidade contextual. Mas, o ensino nas escolas ocorre de modo disciplinar e em um ambiente artificial (FONSECA, 2007; SANTOS, 2009), desconectando o fazer Ciências do ensinar Ciências. O objetivo do Ensino Básico é fornecer elementos para que as pessoas compreendam o mundo que as cerca e exerçam sua cidadania. Para isso, entretanto, compreender o processo de produção de conhecimento e de tecnologia é imprescindível (ZANCAN, 2000).

A compreensão da diferença do pensamento filosófico, conceitos científicos das atividades científicas pode elucidar a crise no Ensino de Ciências (Figura 4). A aplicação do princípio da descrença como pilar básico das estratégicas didáticas pode ser uma alternativa a ser verificada se capaz de promover o ensino de Ciência para o patamar utópico tal como se faz Ciência.

A aquisição e o desenvolvimento de habilidades e competências científicas resultam de atividades práticas, tais como observar, registrar, coletar, desenhar, estudar, listar, buscar, 
identificar, organizar, relacionar, caracterizar, estabelecer, comparar, analisar, supor, hipotetizar, formular, calcular, planejar, experimentar, interpretar, confortar, compreender, responsabilizar-se, valorizar, reconhecer, discordar, concordar, refutar, justificar, concluir, discutir, verificar, comunicar (BRASIL, 1997; MATURANA, 2001; BATISTA, 2006; CARIA; RUIZ, 2009; OLIVEIRA et al., 2009; BRITO; RAMOS, 2014). Pois, é fundamental privilegiar o ensino de atitudes científicas (comportamentos), pois estas habilidades cognitivas complexas são a base da aquisição dos conteúdos conceituais e procedimentais (FURMAN, 2009).

\section{ENSINO DE CIÊNCIAS E A CULTURA DE MASSA}

O desenvolvimento e promoção de atitudes científicas e socioeconômicas sustentáveis está na contramão dos tradicionalismos culturais dogmáticos e da Indústria da Educação de Massa. Esta visa a formação do cidadão-consumidor compulsivo e irrefletido, e para isso usa recursos mitológicos e neuroemocionais altamente persuasivos (WOLF, 1992; BURNHAM; PHELAN, 2002; ZUIN, 2008; SILVA, 2006) tal como um ruído de fundo difuso, se faz presente nos mais variados veículos de comunicação pública, camuflado nas necessidades genuínas humanas e as mesclando a desejos inventados.

A Industria Cultural de Massa tem livre acesso às crianças antes da fase escolar, em etapa de grande vulnerabilidade neurofisiológica (KIPPER, 2011). Os jovens imersos no caldo da Cultura de Massa sofrem a pressão das distorções dos referenciais de sucesso e realização pessoal. Qual é o efeito destes estímulos, se onipresentes, no desenvolvimento do senso de dignidade, das motivações e das atitudes destes jovens quanto aos meios e os fins da Ciência e Tecnologia em suas vidas?

A difusão invisível da crença de que o desenvolvimento econômico depende do consumo em constante crescimento ecoa constantemente a mensagem se parar o bicho come, se correr o bicho pega, criando um mundo imaginário permeado de violência simbólica. Tais estímulos perceptivos, podem estar mantendo e reforçando crenças limitantes acerca dos papeis e desempenhos dos estudantes, professores e escolas frente às demandas do mercado mitológico selvagem e voraz? Um ambiente social impregnado de medo real ou imaginário difuso teria algum papel na manutenção dos tradicionalismos, mesmo disfuncionais, e nas resistências às inovações funcionais? 


\section{ENSINO DE CIÊNCIAS E A NEUROPSICOLOGIA}

Em situação de estresse o cérebro torna-se uma máquina potencializada de fazer crenças (SHERMER, 2012). Nas situações de estresse difuso e constante, natural nos momentos de mudança, a tendência neurofisiológica é adotar o comportamento padrão mais antigo (LUSKIN; PELLETIER, 2008). E essa adoção instintiva do comportamento tradicional pode ser sentida como rejeição ao novo, e assim gerar crises e conflitos intrapessoais entre professores, gestores e estudantes, os quais refletem-se nas inter-relações da comunidade escolares. E esses conflitos, por sua vez, reforçam a utilização das metodologias de ensino tradicionais, na contramão das idealizações causando a sensação de fracasso e, assim, as crenças de que não é possível mudar realimentem-se.

O medo da rejeição do grupo é um dos medos mais primitivos e mais potentes dos seres humanos (SCHUTZ, 1989). O comportamento padrão das pessoas é se ajustar às expectativas do grupo (VITALE, 2006, p. 65). A rejeição ao statu quo, tal como nas propostas de inovações curriculares, tende a ser percebidas inconsciente ou instintivamente pelo grupo como uma ameaça, conflito ou crise (SILVA; MASCARENHAS, 2014; RAMACHANDRAN, 2014). Ainda hoje, em algumas escolas, por hábito ou tradicionalismo, o medo primitivo e instintivo de rejeição do grupo é utilizado para controlar e ditar as regras disciplinadoras e educacionais (ZUIN, 2008).

Os conhecimentos e técnicas de dinâmica de grupos podem contribuir para que os professores entendam as forças de resistências de mudanças atuantes em si próprios e na comunidade escolar (MOSCOVICI, 2013). As pessoas de um grupo se sentem integradas a partir do momento em que participam da tomada de decisões (MAILHIOT, 1970, p. 67). Esse conhecimento pode amparar os professores no desempenho do seu protagonismo insubstituível nas adaptações curriculares cotidianas.

Quais seriam as habilidades para discernir sobre o melhor comportamento a adotar, se o padrão/tradicional ou o polivalente/inovador em cada contexto? A rigorosidade dos métodos investigativos, a precisão da terminologia e a organização sistematizadas dos conhecimentos científicos, caracterizados por padronização estrutural, paradoxalmente, abre espaço para as trocas flexíveis de saberes focados à vivência, à dinâmica do que acontece (BRITO; RAMOS, 2014). Assim, uma reflexão inicial pode advir da prática do relato de vivências experimentais a partir do acontecimento, achado ou invento e suas respectivas consequências sobre a 
natureza ou sobre a sociedade, (BRITO; RAMOS, 2014) por meio da argumentação (SÁ et al, 2014).

A escola ao valorizar as ações de tomada de decisões compartilhadas fomenta o desenvolvimento de habilidades interpessoais, o amadurecimento do senso de dignidade e de democracia. Essas ações podem ser fonte formadora da atmosfera psicossocial contemporânea, que está promovendo a transição da cultura tecnicista à cultura científica, da universidade à multiversidade, do foco dos conteúdos conceituais às atitudes dos estudantes.

\section{ENSINO DE CIÊNCIAS E A CULTURA DE PAZ}

Sabe-se que convicções e certezas absolutas alimentam a violência social (CRAIG; HALTON, 2009; MÜCKE et al., 2011). Os métodos de ensino até a década de 1990 eram justamente, em favor de reforçar a defesa de convicções e certezas absolutas. A escola ao considerar errado o estar com dúvidas e que há um responsável pelas informações verdadeiras e o correto é reproduzi-las o mais rápido possível (na próxima prova) poderia ter contribuído para a formação do cidadão irrefletido, impulsivo, e reativo.

Um caminho para transcender as dificuldades de convívio social pode ser por meio da aprendizagem de duvidar de verdades absolutas e de convicções profundamente arraigada. A educação científica pode contribuir para tal, pois fornece os recursos necessários para se desvencilhar da armadilha que a verdade objetiva e real tece (MATURANA; VARELA, 1995, p.27). Assim, as metodologias de ensino investigativas e reflexivas poderiam contribuir com a cultura da paz, uma vez que ensinam, justamente, os jovens a duvidarem de suas certezas e convicções, coletarem várias versões para um dado fato e exercitarem o diálogo argumentativo (LIBÂNEO, 2015).

Prosperidade intelectual, científica, tecnológica e econômica unicamente não garantem a paz, pois a solidariedade e o senso de dignidade são indispensáveis para o desenvolvimento humano no sentido pleno. "Como as guerras se iniciam nas mentes dos homens, é na mente dos homens que as defesas da paz devem ser construídas" (DELORS et al., 2010, p. 11). A cultura da paz está intrinsecamente relacionada à prevenção e à resolução não violenta dos conflitos, por meio do diálogo, da negociação e da mediação. 


\section{ENSINO DE CIÊNCIAS E A DEMOCRACIA}

No intuito de dar respostas à inquietação pela universalização e democratização do conhecimento, a educação foi repensada com base em quatro princípios-pilares do conhecimento: 1. aprender a conhecer, 2. aprender a conviver, 3. aprender a fazer e 4. aprender a ser (DELORS et al., 2010). Esses princípios-pilares promovem o senso de dignidade, ou seja, a autoconscientização teórica e prática do valor intrínseco de todo ser vivo, que se manifesta em palavras e atos respeitosos dirigido a si próprio e aos outros (LOPES, 2015). A apreensão que o aviltamento à dignidade alheia ultraja a própria dignidade, e que a agressão a própria dignidade ofende a todos, promovem o senso de autoconscientização e autorresponsabilização nos processos coletivos (HICKS, 2013). Em escala social, o reconhecimento deste princípio tem impactos no Direito Civil, promovendo o questionamento do paradigma patrimonialista e a promoção das relações existenciais (BERNARDO, 2006), em escala global, essas ações locais, podem contribuir efetivamente à paz.

A cultura de paz tem por base os valores essenciais à vida democrática, tais como a dignidade humana, o respeito aos direitos e aos deveres, a diversidade cultural, a liberdade, a tolerância, o diálogo, a reconciliação, a solidariedade, a diplomacia, o desenvolvimento pessoal, sustentabilidade econômica e a justiça social (UNESCO, 2010).

\section{ENSINO DE CIÊNCIAS E OS CONTEUDOS ATITUDINAIS}

O dilema ontológico de 'ser' ou 'não ser' fornece elementos à reflexão a respeito da dignidade na escola e da educação escolar. O ser ou não ser vincula-se ao ser aceito ou ser rejeitado, o que na Revolução Industrial era caracterizado por ter ou não emprego (na escola, ter notas). Esse dilema, na atual Revolução Tecnológica, vincula-se ao ser ou não ser percebido (ZUIN, 2008).

A formação escolar que desfoca as lentes perceptivas do estudante aos conteúdos conceituais e ao procedimentais, faz com que este sinta-se não percebido, a vida escolar passa a ocorrer em um estado de não existir. A repressão às necessidades genuínas pode ativar emoções negativas, tristeza e raiva, as quais podem resultar em ressentimento ou apegos às fantasias de grandeza ou contravenções (identificação com super-heróis, anti-heróis ou heróis trágicos) (ZUIN, 2008). 
O resgate das individualidades pode ocorrer por meio da expressão dos medos, angustias frustrações reais; bem como das alegrias, das descobertas e das inovações em um grupo orientado e apto a ouvir esses relatos (ZUIN, 2008; MOSCOVICI, 2013).A partilha de saberes e o hábito de ouvir o parecer dos pares são conteúdos atitudinais relevantes para a formação de sociedade tecnológica segura e ética.

O exercício argumentativo permite que o estudante-cidadão observe, reflita e perceba a própria emocionalidade e intencionalidade frente aos saberes científicos e o contexto social (BRASIL, 1997; LIBÂNEO, 2015). Ao trazer a consciência e a responsabilidade pessoal para o centro das ações cria-se uma nova linha de produtos e serviços escolares (CANDAU; KOFF, 2015), de modo a atendar à necessidade dos estudantes e professores de serem percebidos.

As dicotomias entre professor ou cientista, estudante ou pesquisador, entre ensino ou aprendizagem tem transcendido a novas constelações relacionais. A comunidade escolar tem possibilitado a promoção do estudante e do professor aos papeis de pesquisador, colaborador, inovador, inventor, ou seja, um cidadão múltiplo e ativo na solução de demandas do seu cotidiano (TOLENTINO; ROSSO, 2014; CANDAU; KOFF, 2015). Essas iniciativas mesmo tímidas, são sementes com grande potencial de desenvolvimento social.

Contudo, a priorização na escola do desenvolvimento de competências intrapessoal e interpessoal e a utilização dos conteúdos conceituais e procedimentais como cenários ou coadjuvantes, requer uma certa dose de ousadia, natural ao se contestar o status quo. Novas áreas do saber são requeridas para dar o suporte técnico-científico ao desenvolvimento dos conteúdos atitudinais, tais como a Neurociência, a Neuroética, o Neuromarketing, a Bioética, a Cosmoética, o Direito, o Paradireito, a Paragenética (KIPPER, 2010; PINHEIRO, 2015; VIEIRA, 2014).

A autoestima, autonomia, confiabilidade e segurança na comunidade escolar no ensino básico pode ser a chave para a criação de espaços curriculares propícios a formação promotora da liberdade de análise da realidade e do uso digno da criatividade, dos recursos tecnocientíficos na construção de um mundo ético,seguro e sustentável. Assim, a escola investe-se de sua responsabilidade quando aos fins e aos meios da educação (DELORS et al., 2010). 


\section{CONCLUSÕES}

A partir desta análise panorâmica e multifocal do Ensino de Ciências segundo contextos históricos, sociais, paradigmáticos, culturais, políticos, econômicos e psiconeurológicos, conclui-se:

O processo educacional parece ser paradoxalmente decisivo para delimitar o início e o fim de cada onda revolucionária. O que determinaria o início do próximo ciclo de uma nova onda seriam ações inovadoras pontuais e a conclusão do ciclo se daria pela globalização, e não por totalitarismo ou totalismo de uma dada onda. Com a diversificação de conhecimentos existe a possibilidade de ondas em diferentes esferas do conhecimento surgirem simultaneamente.

As crises paradigmáticas podem decorrer da auto incompreensão dos processos neurofisiológicos e emocionais em respostas a novos estímulos e cenários. Assim, essas crises poderiam ser compreendidas como inadaptações emocionais ou mentais frente às mudanças intelectivas e ideativas, morais ou éticas resultantes da aquisição de novos conhecimentos ou da criação de novos processos de produção. Assim, as inovações tecnocientíficas, paradoxalmente, parecem promover a adoção de uma referência-padrão estabelecendo uma visão de mundo padrão, ou seja, a resistência ao novo.

O Ensino de Ciências pode fazer a profilaxia do mecanismo neurofisiológico de criação de crenças, por meio do uso dos conteúdos conceituais e procedimentais como cenários do processo de ensino-aprendizagem prioritário dos conteúdos atitudinais. Valorizar os conteúdos atitudinais, exercitar a percepção de si próprio e dos pares, existir em primeiro plano, é a base do desenvolvimento social cientifico tecnológico seguro e pacífico.

O Direito de igualdade paradoxalmente vincula-se ao Direito de ser diferente, e.i., a justiça pode ser composta por duas contrapartes: as condições iguais de partida e as diferenças de chegada. A democratização do acesso aos conhecimentos pela tecnologia digital, permite a liberdade de escolhas (igualdade de partida), e naturalmente, promove as diferenças de chegada. Uma vez que há maior liberdade de escolhas, proporcionalmente, também há maior responsabilidade. Contudo, é melhor a escola adotar uma postura conservadora, do que delegar responsabilidades a incapazes. 
O desenvolvimento tecnocientífico, tal como o espaço sideral, criou um mundo cada vez mais diverso e em constante expansão, então, o objetivo de dominar territórios é impraticável, o mais inteligente parece ser investir no desenvolvimento de competências de navegação. O senso de dignidade e de democracia e as metodologias didáticas investigativas e reflexivas podem trazer contribuições aos estudantes e professores para que construam as suas próprias bussolas de busca do $E l$ Dorado ${ }^{4}$ deste novo mundo tecnocientífico que vislumbramos a alvorada.

\section{AGRADECIMENTOS}

Agradeço ao Programa de Pós-Graduação Stricto Sensu em Ensino - Nível Mestrado/PPGEn da Universidade Estadual do Oeste do Paraná - UNIOESTE, Campus de Foz do Iguaçu, e ao Programa Nacional de Pós-Doutorado - PNPD/CAPES.

${ }^{4}$ El Dorado é uma antiga lenda indígena da época da colonização das Américas e atraiu muitos aventureiros europeus. A lenda falava de uma cidade feita de ouro e pedras preciosas. Disponível em: <http://pt.wikipedia.org/wiki/Eldorado> Acesso: 18 abr. 2015. 


\section{REFERÊNCIAS}

ACADEMIA BRASILEIRA DE CIÊNCIAS. O Ensino de ciências e a educação básica: propostas para superar a crise. Rio de Janeiro: Academia Brasileira de Ciências, 2008. 56 p. Disponível em: <http://issuu.com/abciencias/docs/ensino_de_ciencia $>$. Acesso em: 20 jan. 2016.

BARAN, P. On distributed communications. 1964. In FRANCO, A. O poder nas redes sociais. $2^{\text {a }}$ Versão. São Paulo: Escola-de-Redes, 2009. 15 p.

BATISTA, S. H. S. A interdisciplinaridade no Ensino Médico. Revista Brasileira de Educação Médica, Rio de Janeiro, v. 30, n.1, p. 39-45; jan./abr. 2006. Disponível em: <http://www.scielo.br/pdf/rbem/v30n1/v30n1a07.pdf >. Acesso em: 20 jan. 2016.

BERNARDO, W. O. L. O princípio da dignidade da pessoa humana e o novo direito civil: breves reflexões. Revista da Faculdade de Direito de Campos, Ano VII, n. 8, p. 229-267, Jun. 2006. Disponível em: <http://fdc.br/Arquivos/Mestrado/Revistas/Revista08/Artigos/WesleyLousada.pdf>. Acesso em: 20 jan. 2016.

BRASIL. Ministério da Educação. Secretaria de Educação Básica. Ciências da natureza, matemática e suas tecnologias (Orientações curriculares para o ensino médio; volume 2) / Secretaria de Educação Básica.Brasília: Ministério da Educação, Secretaria de Educação Básica, 2006. 135 p. Disponível em: <http://portal.mec.gov.br/seb/arquivos/pdf/book_volume_02_internet.pdf >. Acesso em: 20 jan. 2016.

Ministério da Educação. Secretaria de Educação Fundamental. Parâmetros Curriculares Nacionais: Introdução aos Parâmetros Curriculares Nacionais. Secretaria de Educação Fundamental. - Brasília: Editora MEC/SEF, 1997. 82 p. Disponível em: 〈http://portal.mec.gov.br/seb/arquivos/pdf/livro01.pdf〉. Acesso em: 20 jan. 2016.

BRITO, M. R.; RAMOS, M. N. C. Por Um Ensino e uma Aprendizagem-Acontecimento. Revista Ensaio, Belo Horizonte, v.16, n. 01, p. 31-47, jan./abr. 2014. Disponível em: < http://www.scielo.br/pdf/epec/v16n1/1983-2117-epec-16-01-00031.pdf >. Acesso em: 20 jan. 2016.

BURnham, T.; PHELAN, J. A Culpa é da Genética. Tradução de Vera Maria Whately. Rio de Janeiro: Sextante, 2002. 235 p. Disponível em: <http://www.orelhadelivro.com.br/livros/463338/a-culpa-e-da-genetica/>. Acesso em: 20 jan. 2016.

BUTTURA, E.; NIEMEYER, A. Moisés Bertoni: Uma vida para a Ciências. Foz do Iguaçu: Epígrafe, 2012. $202 \mathrm{p}$.

CANDAU, V. M. F.; KOFF, A. M. N. S. A Didática Hoje: reinventando caminhos. Educação \& Realidade, Porto Alegre, v. 40, n. 2, p. 329-348, abr./jun. 2015. Disponível em: <http://www.scielo.br/pdf/edreal/v40n2/2175-6236-edreal-46058.pdf > . Acesso em: 20 jan. 2016.

CARIA, M.; RUIZ; S. S. Comunicação Científica Intercultural: Olhares Cruzados Sobre os Processos Psicológicos e Comunicacionais. Perspectivas em Ciências da Informação, Belo Horizonte, v. 14, número especial, p. 201-212, 2009. Disponível em: 〈http://www.scielo.br/pdf/pci/v14nspe/a14v14nspe.pdf >. Acesso em: 20 jan. 2016.

CARTER, R. O Livro do Cérebro. Tradução de Frances Jones. Rio de Janeiro, Agir, 2012. 256 p.

CRAIG, I.; HALTON, K. Genetics of human aggressive behaviour. Human Genetic, v. 126, p. 101-113, jun. 2009. Disponível em: 〈http://www.cienciaviva.pt/projectos/2ways/genetics of human.pdf>. Acesso em: 20 jan. 2016.

DELORS, J. et al. (Org.). Educação: um tesouro a descobrir. Brasília: UNESCO, 2010. 43 p. Disponível em: <http://unesdoc.unesco.org/images/0010/001095/109590por.pdf>. Acesso em: 20 jan. 2016.

DUHIGG, C. O Poder do Hábito. Por que fazemos o que fazemos na vida e nos Negócios. Tradução de Rafael Mantovani. Rio de Janeiro: Objetiva, 2012. 407 p. 
ESCOLA DE REDES. Uma rede de pessoas dedicadas à investigação sobre redes sociais e à criação e transferência de tecnologias de netweaving. Organizada por Augusto de Franco desde 2011. Disponível em: <http://escoladeredes.net/>. Acesso em: 20 jan. 2016.

FOnSECA, A. B. Ciências, Tecnologia e Desigualdade Social no Brasil: Contribuições da Sociologia do Conhecimento para a Educação em Ciências. Revista Electrónica de Enseñanza de las Ciencias, España, v. 6. n.2, p. 364-377, 2007. Disponível em: 〈http://reec.uvigo.es/volumenes/volumen6/ART8_Vol6_N2.pdf 〉. Acesso em: 20 jan. 2016.

FRANCO, A. O poder nas redes sociais. 2a Versão. São Paulo: Escola-de-Redes, 2009. 15 p.

FRANCO, A.; LESSA, N. Multiversidade. São Paulo, 2012. 64 p. Disponível em: < http://nethcw.ning.com/page/multiversidade>. Acesso em: 20 jan. 2016.

FUTUYMA, D. J. Biologia Evolutiva. Tradução de Iulo Feliciano Afonso. Ribeirão Preto: FUNPEC Editora, 2009. 830 p.

HICKS, D. Dignidade: o Papel que desempenha na Revolução de Conflitos. Tradução de Fernanda Barrão. Lisboa; Portugal, 2013, 236 p.

INOVAÇÃO TECNOLOGICA. Tudo que aconteçe na fronteira do conhecimento, Campinas, SP, 1999. Disponível em: 〈http://www.inovacaotecnologica.com.br >. Acesso em: 20 jan. 2016.

JABLONKA, Eva; LAMB, Marion J. Evolução em Quatro Dimensões. DNA, Comportamento e a História da Vida. Ilustrações Anna Zeligowski. Tradução Claudio Angelo. São Paulo: Companhia das Letras, 2010.

KHAN, S. Um mundo, uma escola. Tradução de George Schlesinger. Rio de Janeiro: Intrínseca, 2013. 255 p.

KIPPER, D. J. Neuroética: uma disciplina em construção. Revista Bioética, Brasília, v. 19, n. 2, p. 397-420, 2011. Disponível em: <http://revistabioetica.cfm.org.br/index.php/revista bioetica/article/viewFile/636/663 > Acesso em: 20 jan. 2016.

KNAKIEVICZ, T. Empatia, Percepção e Inteligência. Interparadigmas: Revista dos Doutores de Conscienciologia. Foz do Iguaçu, Ano 2, n. 2, p. 83-101, dez. 2014. Disponível em: <http://www.interparadigmas.org.br/wp-content/uploads/2015/06/Interparadigmas-E-PT.pdf $>$. Acessoem: 20 jan. 2016.

Cognitive Structure of Beliefs and Habits: How to Challenge Them? Open Access Library Journal, 2: e2170, dez. 2015. Disponível em: 〈http://www.oalib.com/articles/3153601\#.Vp5lsOgrLcc >. Acesso em: 20 jan. 2016.

A estrutura cognitiva do pensamento científico: uma hipótese de estudo. Interparadigmas: Revista dos Doutores de Conscienciologia. Foz do Iguaçu, Ano 3, n. 3, dez. 2015.

KUHN, T. A estrutura das revoluções científicas. Tradução de Beatriz Vianna Boeira e Nelson Boeira. São Paulo: Editora Perspectiva S.A, $5^{\text {a }}$ edição, 1998.257 p. Disponível em: $<$ https://leandromarshall.files.wordpress.com/2012/05/kuhn-thomas-a-estrutura-das-revoluc3a7c3b5escientc3adficas.pdf $>$. Acesso em: 20 jan. 2016.

LIBÂNEO, J. C. Formação de Professores e Didática para Desenvolvimento Humano. Educação \& Realidade, Porto Alegre, v. 40, n. 2, p. 629-640, abr./jun. 2015. Disponível em: <http://www.scielo.br/pdf/edreal/2015nahead/2175-6236-edreal-46132.pdf >. Acesso em: 20 jan. 2016.

LOPES, A. Senso de Dignidade Cosmoética. In VIEIRA, W. Enciclopédia da Conscienciologiaonline, Foz do Iguaçu, $\quad$ PR, $2015 . \quad$ Disponível em: <http://www.tertuliaconscienciologia.org/index.php?option=com_docman\&Itemid=13> Acesso em: 17 abr. 2015 .

LUSKIN, F.; PELlETIER, K. R. Acabe de Vez com o Estresse: 10 Habilidades Naturais Cientificamente Comprovadas para a Saúde e a Felicidade. Tradução de Maria Cristina Araújo. São Paulo: Francis, 2008. 183 p. 
MAILHIOT, G. B. Dinâmica e Gênese dos Grupos: Atualidades das descobertas de Kurt Lewin. São Paulo: Livraria Duas Cidades, 1970.

MATURANA, H. R. Cognição, ciência e vida cotidiana. Tradução Cristina Magro, Victor Paredes. Belo Horizonte: UFMG, 2001, 203p. Disponível em: < http://www.mettodo.com.br/ebooks/Cognicao_Ciencia_e Vida_Cotidiana.pdf $>$. Acesso em: 20 jan. 2016.

MAturanA, H. R.; VARELA, F. J. A árvore do Conhecimento: As bases Biológicas do Entendimento Humano. Tradução de Jonas Pereita dos Santos Campinas, EditoralPsy II, 1995. 281 p. Disponível em: < http://ruipaz.pro.br/textos/arvoreconhecimento.pdf $>$. Acesso em: 20 jan. 2016.

MOSCOVICI, F. Desenvolvimento Interpessoal: treinamento em grupo. $22^{\mathrm{a}}$ Ed. Rio de Janeiro: José Olympio, 2013

MÜCKE, T.; HEITMANN, H.; KORN, J.; KOSCHMIEDER, C. (Authors/Editors). Taking Responsibility Breaking Away from Hate and Violence. Violence Prevention Network, 2011. Disponível em: <http://www.european-network-of-deradicalisation.eu/publications>. Acesso 31 mar. 2015.

OLIVEIRA, T.; FREIRE, A.; CARVALHO, C.; AZEVEDO, M.; FREIRE, S.; BAPTISTA, M. Compreendendo a aprendizagem da linguagem científica na formação de professores de ciências. Educar, Curitiba, n. 34; p. 19-33, 2009. Disponível em: 〈http://www.scielo.br/pdf/er/n34/02.pdf〉. Acesso em: 20 jan. 2016.

PACHECO, J. Entrevista concedida ao Blog Utopia Educacional. UOL Educação. 12 out. 2009. Disponível em: $<$ http://utopiaeducacional.blogspot.com.br/2009/10/trabalho-ha-mais-de-30-anos-com-escola.html>. Acesso em: 20 jan. 2016.

PINHEIRO, L. Valores evolutivos universais: acervo multidisciplinar. Foz do Iguaçu: Epígrafe, 2015. 440 p.

PROJETO AMORA. Colégio de Aplicação da Universidade Federal do Rio Grande do Sul. Porto Alegre, RS. Disponível em: <http://www.ufrgs.br/projetoamora >. Acesso em: 20 jan. 2016.

RAMACHANDRAN, V.S. O que o Cérebro tem para Contar: Desvendando os mistérios da natureza humana. Tradução Maria Luiza X. de A. Borges. Rio de Janeiro: Zahar, 2014. 434 p.

REVONSUO, A. Consciousness: the science of subjectivity. New Yor: Psychology Press, 2010. 324 p.

RIBAS, G. C. Considerações sobre a Evolução filogenética do sistema nervoso, o comportamento e a emergência da consciência. Revista Brasileira de Psiquiatria, São Paulo, v. 28, n. 4, p. 326-38, Edição Especial, 2006. Disponível em: <http://www.scielo.br/pdf/rbp/v28n4/12.pdf>. Acesso em: 20 jan. 2016.

SÁ, L. P.; KASSEBOEHMER, A. C.; QUEIROZ, S. L. Esquema de argumento de Toulmin como instrumento de ensino: explorando possibilidades. Revista Ensaio, Belo Horizonte, v.16, n. 03, p. 147-170, set/dez. 2014. http://www.portal.fae.ufmg.br/seer/index.php/ensaio/article/viewFile/1879/1515.

SANTOS; M. E. V. M. Ciência como Cultura: Paradigmas e Implicações Epsitemológicas na Educação Científica Escolar. Química Nova, São Paulo, v. 32. n. 3, p. 530-537, jan. 2009. Disponível em: <http://www.scielo.br/pdf/qn/v32n2/v32n2a43.pdf >. Acesso em: 20 jan. 2016.

SCHUTZ, W. C. Profunda Simplicidade - Uma nova consciência do eu interior. Tradução de Maria Silvia Mourão Netto. São Paulo: Ágora, 1989. 200 p.

SEMLER, R.; DIMENSTEIN, G.; COSTA, A. C. G. Escola sem sala de aula. Papirus, 2004. 140 p.

SHELDRAKE, R. Ciência sem Dogmas. A Nova Revolução Científica e o Fim do Paradigma Materialista. Tradução Mirtes Frange de Oliveira Pinheiro. São Paulo: Cultrix, 2014. 400 p.

SHERMER, M. Cérebro \& Crença. De Fantasmas e Deuses à Política e às Conspirações - Como Nosso Cérebro Constrói Nosssas Crenças e as Transforma em Verdades. Tradução de Eliane Rocha. São Paulo: JSN Editora, 2012. 392 p. 
SILVA, J. L.; MASCARENHAS, S. A. Análise de Atribuições Causais para o Bullying - Uma Pesquisa com Estudantes do Ensino Fundamental de Humaitá-AM. Revista EDUCAmazônia - Educação Sociedade e Meio Ambiente, Belém, ano 7, v. XIII, n. 2, p. 115-135, jul./dez. 2014. Disponível em:

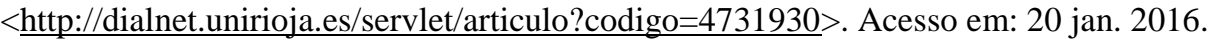

SILVA, P. R. Consciência e Abundância. Paulo Roberto da Silva: Niterói, 2006. 192 p. Disponível em: $<$ http://www.projetocapacitacaomarica.uff.br/sites/default/files/Consci\%C3\%AAncia\%20e\%20Abund\%C3\%A2 ncia.pdf $>$. Acesso em: 20 jan. 2016.

SILVEIRA, F. L. A filosofia da Ciência de Karl Popper: Racionalismo Analítico. Caderno Brasileiro de Ensino de Física, Florianópolis, v.13, n.3, p. 197-218, dez. 1994. Disponível em: <https://periodicos.ufsc.br/index.php/fisica/article/view/7046>. Acessoem: 20 jan. 2016.

SLUTKIN, G. Cure Violence: Violence is a Health Issue. Disponível em: <http://cureviolence.org/post/staff/gary-slutkin/>. Acesso: 30 mar. 2015.

TOFFLER, A. A terceira onda. Tradução de João Távora Rio de Janeiro: Editora Record, 2012. 491 p.

TOLENTINO, P. C.; ROSSO, A. J. As Representações Sociais dos Licenciandos em Ciências Biológicas sobre o Ser Biólogo e o Ser Professor. Revista Ensaio, Belo Horizonte, v.16, n. 03, p. 15-33, set./dez. 2014. Disponível em: 〈http://www.portal.fae.ufmg.br/seer/index.php/ensaio/article/viewArticle/1511〉. Acesso em: 20 jan. 2016.

UNIAMÉRICA. A Faculdade União das Américas. Foz do Iguaçu, PR. Disponível em: <http://www.uniamerica.br/>. Acesso em: 20 jan. 2016.

VIEIRA, W. Dicionário de Neologismos da Conscienciolgia. Lourdes Pinheiro (Org.). Foz do Iguaçu: Editates, 2014. 1072 p.

VILLA, F. Primeira transferência: afastar a sugestão do somático. Ágora, Rio de Janeiro, v. XI n. 2, p. 333347, jul./dez. 2008. Disponível em: 〈http://www.scielo.br/pdf/agora/v11n2/a11v11n2.pdf >. Acesso em: 20 jan. 2016.

VITALE, J. O manual de instruções que você deveria ter recebido ao nascer. Tradução de Savannah Hartman. São Paulo: Landscape, 2006. 200 p.

WOLF, N. O mito da beleza: Como as imagens de beleza são usadas contra as mulheres. Tradução Waldéa Barcellos. Rio de Janeiro: Rocco, 1992. 439 p. Disponível em: < http://brasil.indymedia.org/media/2007/01/370737.pdf > . Acesso em: 20 jan. 2016.

ZANCAN. G. T. Educação para a transformação. In: WERTHEIN, Jorge; CUNHA, Célio (Orgs.). Ensino de Ciências e Desenvolvimento: O que Pensam os Cientistas. 2. Ed. Brasília: UNESCO, Instituto Sangari, 2009.Disponível em: <http://unesdoc.unesco.org/images/0018/001859/185928por.pdf>. Acesso em: 20 jan. 2016.

ZUIN, A. A educação de sísifo: sobre ressentimento, vingança e amok entre professores e alunos. Educação Social, Campinas, v. 29, n. 103, p. 583-606, mai./ago, 2008. Disponível em: <http://www.scielo.br/pdf/es/v29n103/14.pdf $>$. Acesso em: 20 jan. 2016. 